Journal of Organometallic Chemistry, 199 (1980) 293-297

Elsevier Sequoia S.A., Lausanne - Printed in The Netherlands

\title{
APPLICATION OF ALLENYLSILVER(I) COMPOUNDS IN ORGANIC SYNTHESIS. A SIMPLE ROUTE TO SUBSTITUTED ALLENES
}

H. WESTMIJZE, H. KLEIJN, H.J.T. BOS and P. VERMEER

Department of Organic Chemistry, State University of Utrecht. Croesestraat 79, 3522 AD Utrecht (Tize Netherlands)

(Received May 13th, 1980)

\section{Summary}

Allenylsilver(I) compounds, prepared in situ by addition of alkylsilver(I)lithium bromide complexes to butenynes, readily react with a variety of electrophiles. The produced compounds are usually almost pure allenes, but in some cases substantial amounts of the isomeric acetylenes are also formed.

\section{Introduction}

In the literature considerable attention has been focussed on reactions of allenyl-metal compounds, $=\mathrm{C}=\mathrm{C}=\overrightarrow{\mathrm{C}}-\mathrm{M}$, with electrophiles, " $\mathrm{E}$ "". The reported data do not establish a general pattern of reactivity, however. In some reactions acetylenes, $=\mathrm{C}(\mathrm{E})-\mathrm{C} \equiv \mathrm{C}-$, are mainly produced, in other reactions formation of<smiles>[R]C=C=C([R])C[R]</smiles> 
allenes, $=\mathrm{C}=\mathrm{C}=\stackrel{\mathrm{C}}{\mathrm{C}}-\mathrm{E}$, is preferred [1].

Allenylsilver(I) reagents have not received much attention, thus far. We recently showed that these allenyl-metal compounds can be readily obtained by treating conjugated enynes with alkylsilver(I)-lithium bromide complexes, $\mathrm{RAg} \cdot 2 \mathrm{LiBr}$ [2]. Protolysis of such allenylsilver(I) compounds gives allenes. On the other hand, acetylenes were produced when these silver(I) reagents were allowed to react with carbon disulfide [3].

The present paper deals with a more extensive study of the behaviour of allenylsilver(I) compounds towards electrophiles.

\section{Results and discussion}

The allenylsilver(I) compounds $I$, obtained from $H_{2} C=C\left(R^{\prime}\right)-C \equiv C H\left(R^{\prime}=H\right.$ or $\mathrm{Me}$ ) and $\mathrm{RAg} \cdot 2 \mathrm{LiBr}[1] *$, appeared to react regioselectively with a large variety of electrophiles $\mathrm{E}-\mathrm{Z}$, viz. cyanogen bromide, iodine, methyl methanethiolsulfonate, allyl bromide, and the halides $\mathrm{Me}_{3} \mathrm{M}-\mathrm{Cl}(\mathrm{M}=\mathrm{Si}, \mathrm{Ge}$, and $\mathrm{Sn})$. Analysis of the products showed that these electrophiles strongly preferred to react at the allenic end of I to give allenes II (see Scheme 1; E in II: $\mathrm{Br}, \mathrm{I}, \mathrm{MeS}$, $\mathrm{H}_{2} \mathrm{C}=\mathrm{CH}-\mathrm{CH}_{2}-$, and $\mathrm{Me}_{3} \mathrm{M}$, respectively). Generally, the amount of isomeric 1-alkynes III, compounds resulting from propargylic attack by the electrophile, was less than $5 \%$; in case of bromination of $I\left(R=t-B u, R^{\prime}=H\right)$ by cyanogen bromide the ratio II/III was somewhat lower, viz. 90/10. The total yield of II + III in all cases was in the range $80-90 \%$ (calculated on $\mathrm{RAg} \cdot 2 \mathrm{LiBr}$ ).

In the same study we also attempted to prepare allenyl bromides by allowing I to react with $N$-bromosuccirimide (NBS). Although this reaction also proceeded smoothly, the ratio II/III was not as high as that in the corresponding reaction with cyanogen bromide. For instance, treatment of $I\left(R=t-B u, R^{\prime}=\right.$ Me) with NBS led to a mixture of II and III in a ratio $80 / 20$, while that with cyanogen bromide gave almost exclusively II (ratio II/III: >95/5). Reaction of the same silver(I) compound with $N$-chlorosuccinimide (NCS) gave mainly acetylene III ( $\mathrm{E}=\mathrm{Cl}$; ratio II/III: 25/75).

SCHEME 1

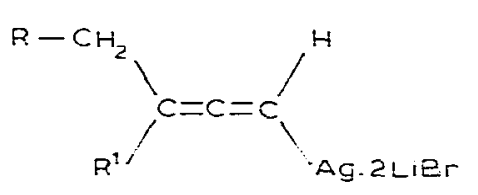

(I)

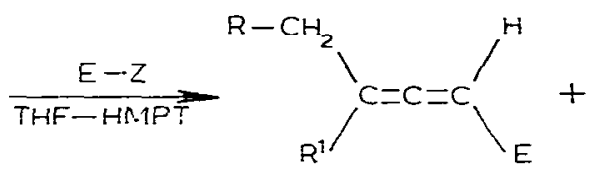

(II)

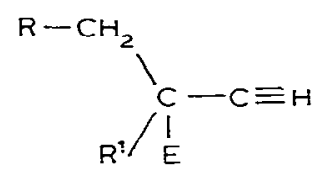

(III)

$$
\begin{aligned}
& (\mathrm{R}=\mathrm{Bu}, \mathrm{i}-\mathrm{Pr}, \mathrm{t}-\mathrm{Bu} ; \\
& \mathrm{R}^{\mathrm{T}}=\mathrm{H} \text { or } \mathrm{Me} ; \mathrm{E}-\mathrm{Z}=\mathrm{Br}-\mathrm{CN}, \mathrm{I}_{2}, \mathrm{MeS}-\mathrm{SO}_{2} \mathrm{Me}, \\
& \mathrm{H}_{2} \mathrm{C}=\mathrm{CH}-\mathrm{CH}_{2} \mathrm{Br}, \mathrm{Me} \mathrm{Si}_{3}-\mathrm{Cl}, \mathrm{Me}_{3} \mathrm{Ge}-\mathrm{Cl}, \mathrm{Me}_{3} \mathrm{Sn}-\mathrm{Cl} \text {. NBS, NCS ? }
\end{aligned}
$$

Attempts to alkylate $\mathrm{I}$ in THF-HMPT by methyl iodide were not successful. For instance, when $I\left(R=t-B u, R^{\prime}=M e\right)$ was allowed to react with methyl iodide,

* These additions were performed in a mixture of tetrahydrofuran (THF) and hexamethylphosphoric triamide (HMTPT). 
a mixture of high-boiling products was obtained, presumably consisting of dimers derived from I. So, allenylsilver(I) compounds are considerably less prone to alkylation than their lithium and copper analogs, which can be alkylated readily [4-5].

In the introduction it was noted that carbon disulfide is introduced at the propargylic site of I. In contrast, carbon dioxide appears to react at the allenic site of I, with formation of nearly pure allenyl carboxylic acids (compounds IV in Scheme 2):

SCHEME 2

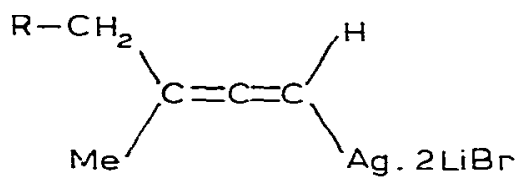

(I)

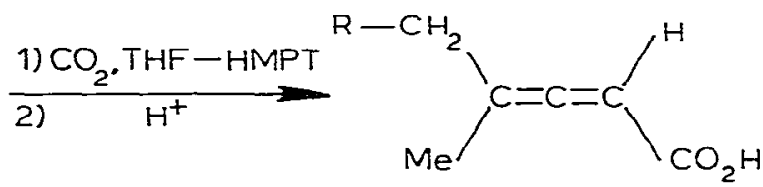

(IV)

$(\mathrm{R}=\mathrm{i}-\mathrm{Pr}$, yield of $\mathbb{Z}: 85 \%$;

$R=t-B u, y i e l d$ of $\mathbb{Z}: 90 \%$ )

Physical constants and some characteristic spectroscopic data for allenes II and IV are given in Table 1.

The results show that most of the electrophiles studied are preferentially introduced at the allenic end of compounds $I$, although in some cases, viz. reaction of I with NCS and carbon disulfide, introduction of the electrophile at the propargylic site is favoured. This implies that the regiochemistry observed for reactions of I with electrophiles, cannot fully be rationalized with Pearson's hard and soft acid and base principle (HSAB, [6]). Using this principle, one would namely predict that soft electrophiles (e.g. $\mathrm{CS}_{2}, \mathrm{I}_{2}$, allyl bromide, MeS$\mathrm{SO}_{2} \mathrm{Me}$ etc.) are preferentially introduced at the "sof $t$ " end of I and hard ones (e.g. $\mathrm{H}_{2} \mathrm{O}, \mathrm{CO}_{2}, \mathrm{Me}_{3} \mathrm{Si}-\mathrm{Cl}$ etc.) at the "hard" end of I. Most Iikely, the propargylic site of $I$ is, in HSAB-terms, softer than its allenic one because of higher $p$ character at the propargylic site. (This assumption was also made for allenyllithium compounds [1].)

For reactions with electrophiles of the soft series, only that of I with carbon disulfide (see Introduction), would fit the HSAB-principle; reaction of I with the other electrophiles does not. Most of the hard electrophiles used in this paper, and also $\mathrm{H}_{2} \mathrm{O}$ (sce ref. 2), react preferentially at the "hard", allenic end of $\mathrm{I}$, but NCS (which is undoubtedly "hard") mainly gives the product which would be predicted for soft electrophiles. With respect to the latter reaction is it noteworthy that NBS, which is softer than NCS, gives more allenic product than NCS.

These data show that when used alone the HSAB-explanation breaks down, especially when applied to reactions of I with soft electrophiles. Creary [1] has also observed an inconsistency with the HSAB-principle for reactions of 3,3dimethylallenyllithium with certain electrophiles. He suggested that other factors such as steric hindrance, charge distribution in the allenylmetal compounds, and the stability of the allene relative to the acetylenic product, can play a large part in determining the acetylene-allene ratios. 


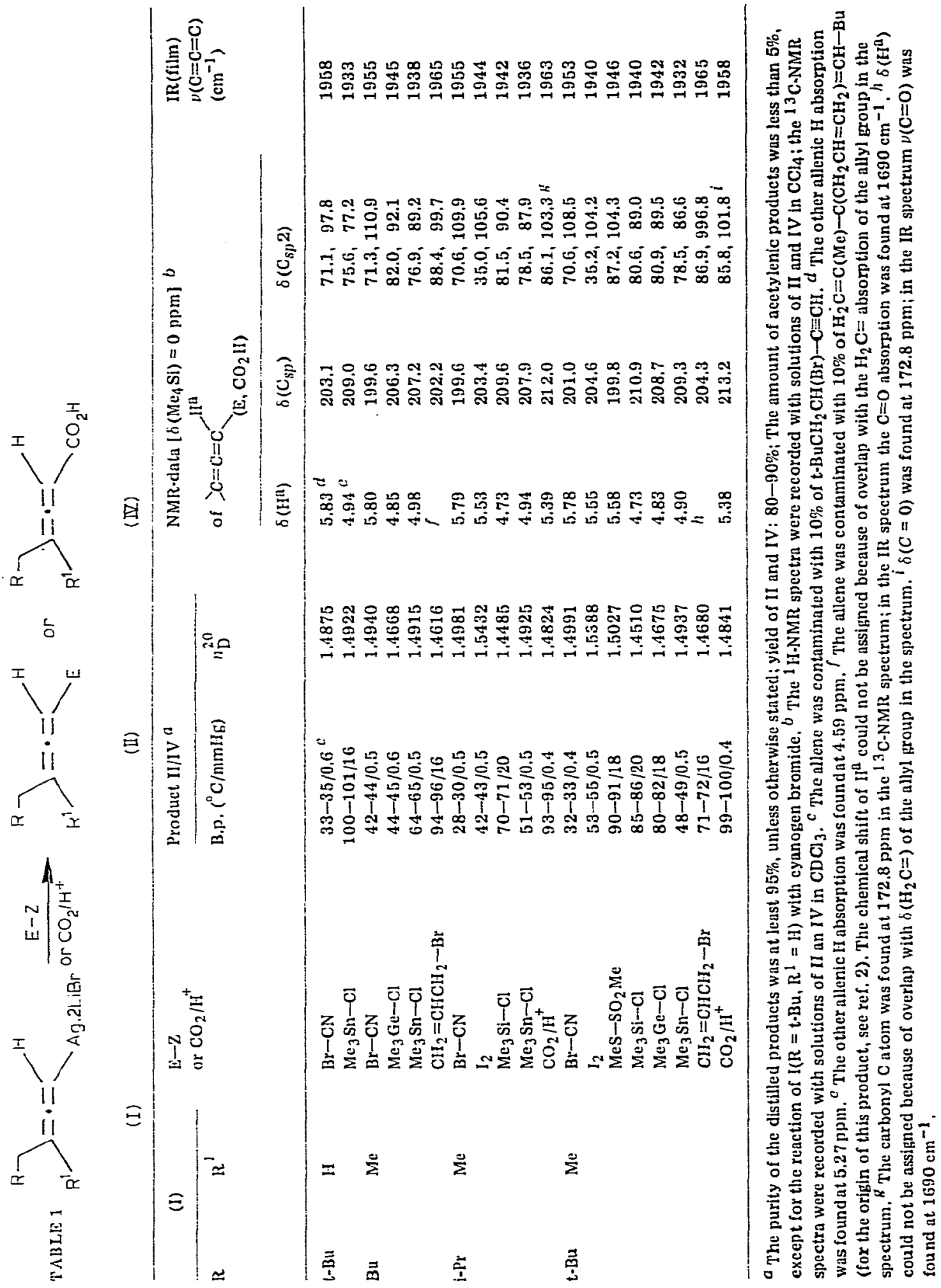




\section{Experimental}

All reactions were performed under dry nitrogen. The products were analysed by GLC (SE 33 column) and by NMR (Varian EM-390 and CFT-20 spectrometers) and IR spectroscopy.

\section{(1) Preparation of the silver(I) compounds, $I$}

To a stirred solution of $\mathrm{RAg} \cdot 2 \mathrm{LiBr}(0.030 \mathrm{~mol}) *$ in a mixture of THF (180 $\mathrm{ml})$ and HMPT (18 ml) an appropiate amount of $\mathrm{H}_{2} \mathrm{C}=\mathrm{C}\left(\mathrm{R}^{1}\right)-\mathrm{C} \equiv \mathrm{CH}(0.060 \mathrm{~mol}$; $R^{1}=H$ or Me) was added at $-60^{\circ} \mathrm{C}$. The resulting mixture was stirred for $3 \mathrm{~h}$ at $-20^{\circ} \mathrm{C}\left(\mathrm{R}=\mathrm{t}-\mathrm{Bu} ; \mathrm{R}^{1}=\mathrm{H}\right.$ or $\left.\mathrm{Me}\right)$, for $3 \mathrm{~h}$ at $0^{\circ} \mathrm{C}\left(\mathrm{R}=\mathrm{i}-\mathrm{Pr} ; \mathrm{R}^{1}=\mathrm{Me}\right)$, or for $6 \mathrm{~h}$ at $0^{\circ} \mathrm{C}\left(\mathrm{R}=\mathrm{Bu} ; \mathrm{R}^{1}=\mathrm{Me}\right)$.

\section{(2) Reaction of I with $E-Z$}

To a stirred solution of adducts I obtained as described in (1) the electrophile $\mathrm{E}-\mathrm{Z}(0.030 \mathrm{~mol})$ was added at $-50^{\circ} \mathrm{C}$. After stirring of the mixture for $1 \mathrm{~h}$ at $-50^{\circ} \mathrm{C}$, the temperature of the reaction mixture was allowed to rise to $25^{\circ} \mathrm{C}$. Stirring at $25^{\circ} \mathrm{C}$ was continued for $1 \mathrm{~h}\left(\mathrm{E}-\mathrm{Z}=\mathrm{Br}-\mathrm{CN}, \mathrm{I}_{2}\right.$, or $\left.\mathrm{MeS}-\mathrm{SO}_{2} \mathrm{Me}\right), 2 \mathrm{~h}$ $\left(\mathrm{E}-\mathrm{Z}=\right.$ allyl-Br, $\mathrm{Me}-\mathrm{I}$, NCS, or NBS), or $40 \mathrm{~h}\left(\mathrm{E}-\mathrm{Z}=\mathrm{Me}_{3} \mathrm{Si}-\mathrm{Cl}, \mathrm{Me}_{3} \mathrm{Ge}-\mathrm{Cl}\right.$, or $\mathrm{Me}_{3} \mathrm{Sn}-\mathrm{Cl}$ ). Subsequently, the mixture was added to a solution of ammonium chloride in water containing $\mathrm{NaCN}(2 \mathrm{~g})$. The products were isolated by extraction with pentane $(3 \times 50 \mathrm{ml})$. After washing the combined extracts with water $(5 \times 100 \mathrm{ml})$ and drying with $\mathrm{MgSO}_{4}$ the solvent was distilled off and the products were analysed. Physical constants and spectroscopic data of the distilled compounds II are given in Table 1.

\section{(3) Reaction of $\mathrm{I}$ with $\mathrm{CO}_{2}$}

A dry $\mathrm{CO}_{2}$ stream (50 $\left.\mathrm{ml} / \mathrm{min}\right)$ was bubbled through the under (1) obtained THF-HMPT solution of $I\left(\sim 0.03 \mathrm{~mol}, \mathrm{R}=\mathrm{i}-\mathrm{Pr}\right.$ or $\left.t-\mathrm{Bu} ; \mathrm{R}^{1}=\mathrm{Me}\right)$, initially for $1 \mathrm{~h}$ at $-50^{\circ} \mathrm{C}$ and subsequently for $1 \mathrm{~h}$ at $25^{\circ} \mathrm{C}$. The mixture was then treated with $1 \mathrm{~N} \mathrm{HCl}$. The produced carboxylic acids IV were extracted with ether $(5 \times 50 \mathrm{ml})$; the combined extracts were washed with $1 N$ IICl $(3 \times 50 \mathrm{ml})$, dried with $\mathrm{MgSO}_{4}$, and concentrated in vacuo. The residues were distilled. Physical constants and some characteristic spectroscopic data of IV are given in Table 1.

\section{Acknowledgement}

This investigation was supported by the Netherlands Foundation of Chemical Research (SON) with financial aid from the Netherlands Organization for the Advancement of Pure Research (ZWO).

\section{References}

1 X. Creary. J. Amer. Chem. Soc., 99 (1977) 7632, and references cited therein.

2 H. Westmijze, H. Kleijn, and P. Vermeer, J. Organometal. Chem., 172 (1979) 377.

3 H. Westmijze, K. Ruitenberg, J. Meijer, and P. Vemeer. Tetrahedron Lett., 21 (1980) 1771.

4 G. Linstrumelle and D. Michelot, J. Chem. Soc.. Chem. Commun., (1975) 561.

5 D. Michelot and $G$. Linstrumelle, Tetrahedron Lett., (1976) 275.

6 R.G. Pearson, J. Chem. Educ., 45 (1968) $581,643$.

* $\mathrm{KAg} \cdot 2 \mathrm{LiBr}$ was prepared from $\mathrm{RMgX}$ and $\mathrm{AgBr} \cdot 2 \mathrm{LiBr}$ in THF-HMPT according to our procedure given in rei. 2 . 